\title{
A different way to think about creativity: the case of autism and Outsider Art
}

\author{
mckenzie or stancer, rebecca
}

http://hdl.handle.net/10026.1/12018

10.1163/9781848881273_012

inter-disciplinary.net

All content in PEARL is protected by copyright law. Author manuscripts are made available in accordance with publisher policies. Please cite only the published version using the details provided on the item record or document. In the absence of an open licence (e.g. Creative Commons), permissions for further reuse of content should be sought from the publisher or author. 


\section{A different way to think about creativity: the case of autism and Outsider Art}

\section{Rebecca McKenzie}

People with Autism Spectrum Conditions are said to exhibit a lack of creativity and fantasy in thought processes. This view is reflected in internationally accepted diagnostic criteria for the condition: 'Most individuals with autism lack spontaneity, initiative, and creativity...' (ICD-10 WHO; 1992). Psychological measures such as the Torrance test are commonly used to assess the artistic creativity of individuals. These tests measure the quantity of novel creative outputs an individual is capable of generating within a limited time span. Such approaches equate divergent thinking with creativity in the sense that the focus is not on the quality of output, but the rapid generation of numerous solutions to a creative 'problem.' This paper questions psychological methods of assessing creativity, drawing on historical and contemporary works of art. Within the world of art, creativity is routinely assessed in terms of quality rather than quantity. Artistic genius is often associated with the obsessive concern with a single subject or the use of repetitive imagery. For example, Warhol, Cézanne and Picasso created numerous works of art which demonstrate an obsessive interest in a single subject matter explored from subtly different perspectives. An obsessive or repetitive approach to creativity is very much in keeping with what is known about the world view of many people with autism. Contrary to psychological assessments of the creative output of individuals with autism, evidence in support of a rich creative potential within this special population will be presented. Such evidence includes the work of internationally renowned artists with autism, contemporary interest in this population by the Outsider Art Movement and the everyday creative pursuits of young people with autism in educational settings.

creativity, art, autism, outsider, psychology, Torrance, artist, adolescent

$* * * * *$

Understanding of Autism Spectrum Conditions (ASC) relies heavily upon psychological measures and interpretations. This chapter questions psychological definitions of creativity and experimental tasks used to assess it. An important subtext of the current discussion is the proposal that a broader definition may help to alleviate the apparent disparity between diagnostic criteria for autism and the success of individuals with autism within the art world.

It has long been known that people with autism may have islets of special abilities including savant skills in art. One of many examples is Stephen Wiltshire. 
Stephen creates internationally acclaimed city scenes, has his own gallery in London and is currently exhibiting at the UBS gallery in New York (see Image 1).

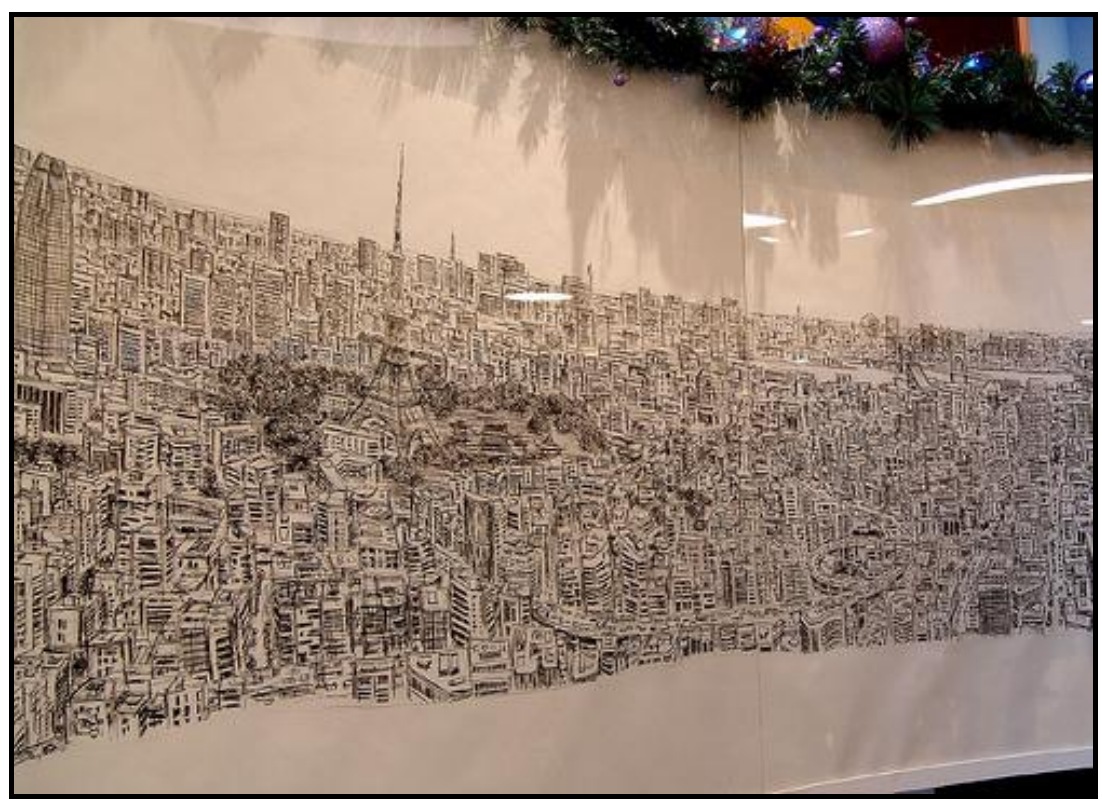

Image 1- 'Tokya' Stephen Wiltshire (2005). Courtesy of www.autism.wikia.com. Licensed under Creative Commons Attribution 2.5 License: http://creativecommons.org/licenses/by/2.5/

The work of artists with autism and related conditions has also been brought to popular attention via the Outsider Art Movement. ${ }^{1}$

"Art Brut", or "outsider art", consists of works produced by all kinds of dwellers on the fringes of society. Working outside fine art "system" these people have produced, from the depths of their own personalities and for themselves and no one else, works of outstanding originality in concept, subject and techniques. ${ }^{2}$

Whilst outsider artists may exist on the periphery of society, the movement itself is far from marginal, with major exhibitions across the globe, an international journal focusing on Art Brut, Outsider Art and Folk Art (Raw Vision- International Journal of Intuitive and Visionary Art), A collection of key works at Tate Britain and the Outsider Art Fair held annually in New York. Artists with autism who are 
associated with the Outsider Art Movement demonstrate highly original, imaginative work expressed through a variety of styles ranging from realist to abstract (see Image 2).

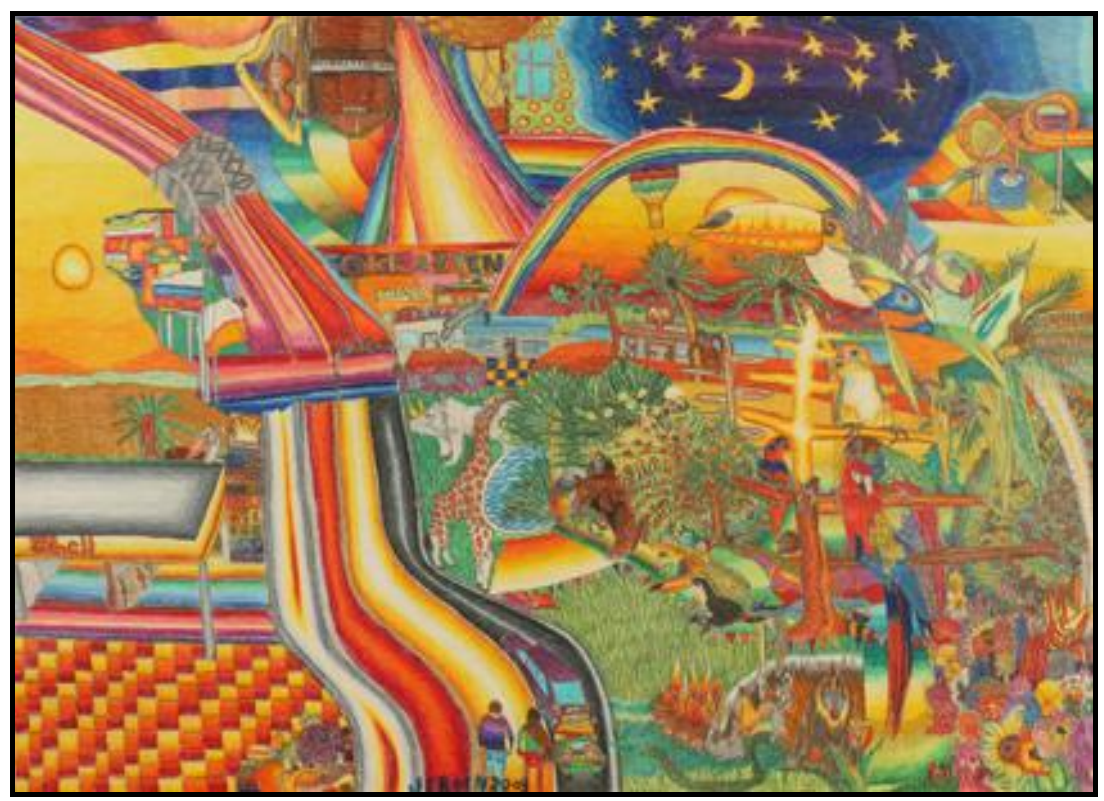

Image 2- 'Fruit trees with parrots' Jeroen Pomp (2009). Courtesy of Galerie Atelier Herenplaats

Observations of creativity among people with ASC are not limited to autistic savants or individuals recognised by the art community. Many practitioners in everyday educational settings also report imaginative and innovative artistic abilities among children and adolescents with autism. Creative media include drawing, painting, drama and animation. ${ }^{34}$ Similar reports also come from parents of children with autism ${ }^{5}$ who often propose that art offers a means of communication for their children (See Image 3). The celebration of the creativity of artists with autism and related conditions within the art world is in contrast with the psychological view of the condition. Diagnostic guidelines for childhood autism, provided by the International Statistical Classification of Diseases and Related Health Problems state that 'Most individuals with autism lack spontaneity, initiative, and creativity in the organization of their leisure time" and demonstrate "a relative lack of creativity and fantasy in thought processes. ${ }^{6}$ 


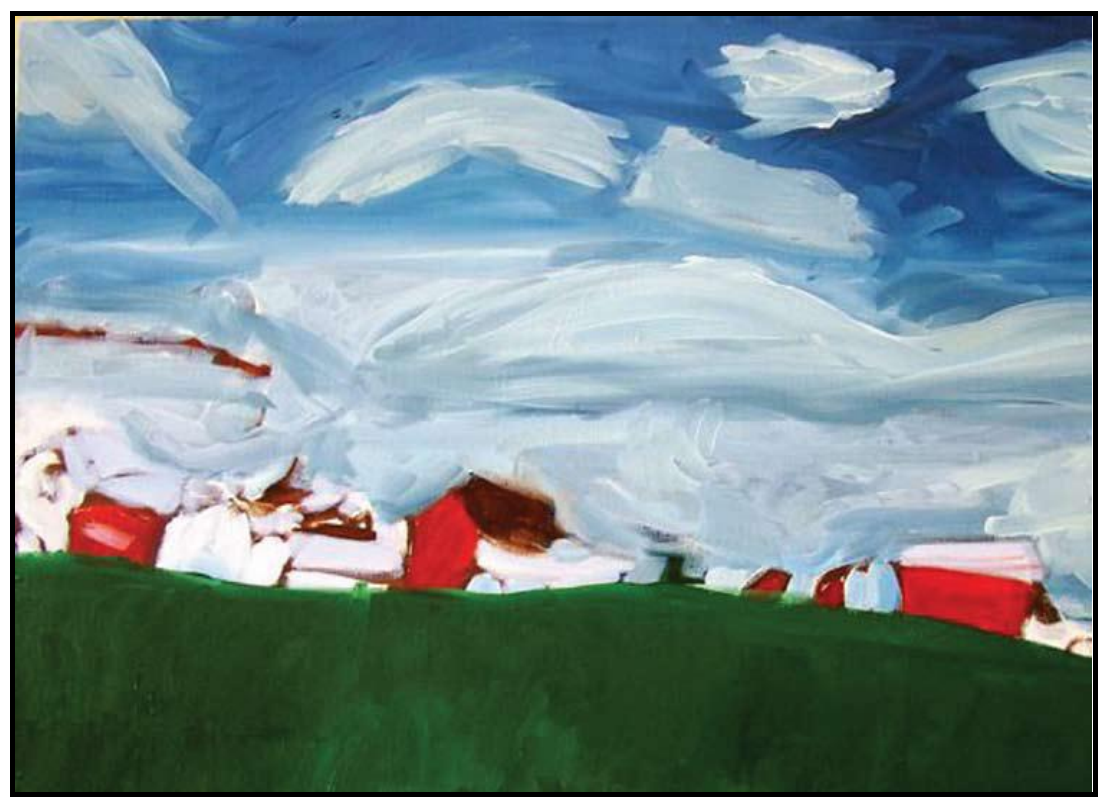

Image 3- 'Windy windy day' Kevin Hosseini age 10 years (2005). Courtesy of Debra Hosseini

Diagnostic criteria are supported by a number of psychological studies demonstrating that people with autism lack imagination, creativity and the ability to generate novel thoughts. ${ }^{78910}$ Such studies tend to be based upon a limited repertoire of measures which rely heavily upon the assessment of divergent thinking, the ability to generate numerous solutions to a creative 'problem' often within a limited time span. Such tasks include the widely used Torrance tests; ${ }^{11}$ the design fluency test ${ }^{12}$ and the Creativity Assessment Packet (CAP). ${ }^{13}$ Generally participants are given a visual stimulus such as a triangle or squiggle and asked to expand upon the figure to create as many distinct designs as possible within a given time span (see Image 4). The non-verbal Torrance tests of creative thinking includes a number of tasks of this type including the Creative Design Task where participants are asked to create as many novel designs as possible in half an hour from a set of coloured circles and strips. Similarly, both the CAP and the Torrance test include an incomplete figures task which requires participants to use shapes or lines in as many novel ways as possible to create a number of designs in less than 30 minutes. 


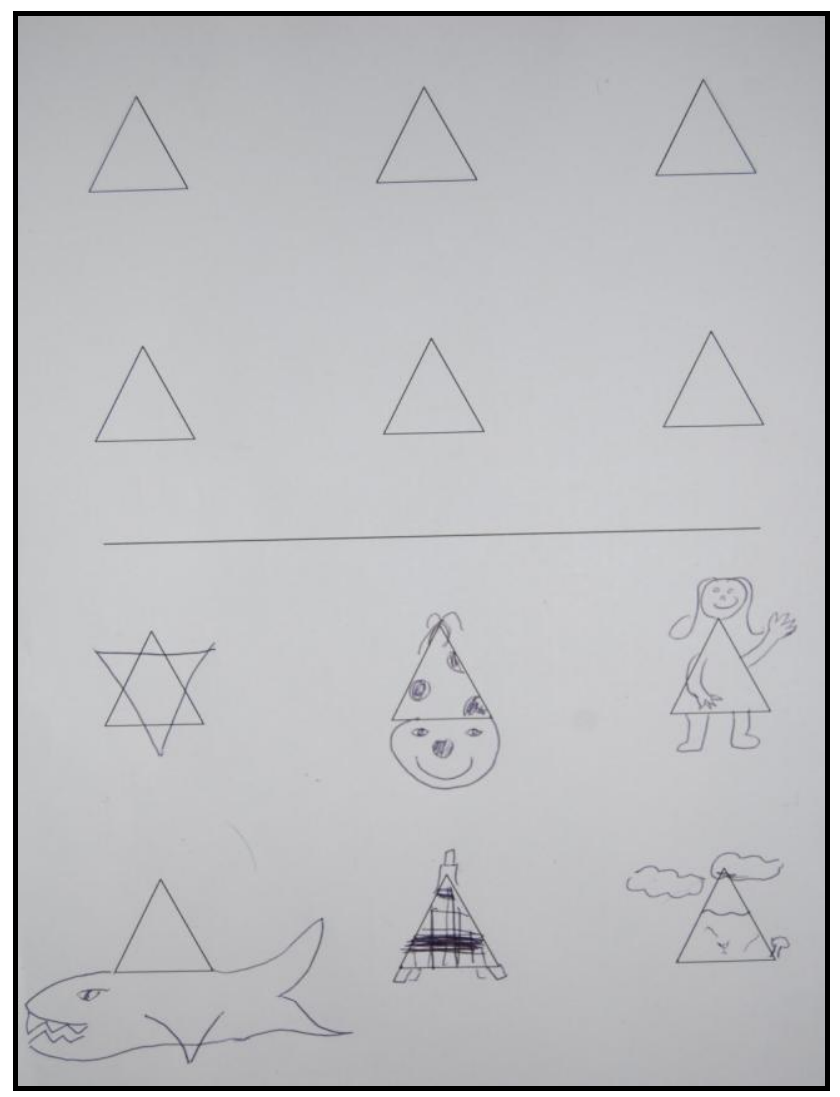

Image 4- Creativity task (2011). Courtesy of Florence McKenzie

A slightly different body of tasks provides a stimulus, then assesses the output on a pass/fail or points basis. For example, in the 'magic door' version of Karmiloff- Smith's drawing task, participants are told that passing through a special door changes individuals into 'funny, strange looking people that no one has ever seen before'. ${ }^{14}$ Participants are then asked to draw as many examples as possible of people who have passed through the door. Scoring is based on how many 'imaginative' features a drawing may have. Consequently, a man with antennae will score less than a man with paws and antennae. Transformation tasks require participants to change a given image into something else. Here scoring relies on a pass or fail basis depending on the degree of change. A balloon made into a face would pass, but a plain balloon made into a stripy balloon would not. An important feature of these tasks which is also common to the Torrance type 
tests is that images deemed to be too similar to each other or to the stimulus are not counted. Hence, across all of these tasks, those individuals judged to be most creative will create numerous responses to a given stimuli, often in a short space of time, and those responses will be very clearly distinct. Individuals with ASC perform very poorly on these types of tests. Children with autism show impairment in designing unreal beings ${ }^{15}$ tending to produce fewer unreal entities and creating images that are highly associated with each other. ${ }^{16}$ They also perform poorly on transformation tasks. Craig, Baron-Cohen and $\mathrm{Scott}^{17}$ found that children with autism tended to produce transformations which either failed to change the object discernibly or resulted in outcomes which were highly similar to the stimulus. Participants with autism also perform poorly on the Torrance tests, again providing fewer outcomes judged to be novel compared to typical participants i.e. sufficiently dissimilar to previous designs. ${ }^{18}$

A recent detailed study of creativity among children with Asperger Syndrome (AS), a form of ASC, may shed some light on why children with autism perform poorly on these tasks. ${ }^{19}$ Children with AS and typically developing children were presented with The Creativity Assessment Packet (including the incomplete figures task). Compared to typically developing children, children with AS produced elaborate, detailed pictures which were highly associated with a particular area of interest. Such an approach is likely to reflect a well-documented tendency among individuals with ASC to have a detail-based rather than holistic processing style. ${ }^{20}$ In addition, people with autism often have very restricted, obsessive areas of interest. A further study assessed creativity scores among savant artists, talented individuals with ASC, MLD and typically developing art students using the Torrance tests. The savants showed more elaborate responses, but the art students scored more highly on all other measures creating more responses overall. The Elaboration measure assessed the amount of detail added to a particular design and this was highlighted as a possible core feature of savant art success. Similar results were found in an earlier study by Duckett. ${ }^{21} \mathrm{~A}$ key factor in understanding this problem is the different ways creativity is conceptualised by psychologists and artists. The psychological view of creativity expressed through measures of divergent thinking presents creativity and imagination as being essentially quantifiable. The tasks under discussion provide scores on the basis of how many novel designs can be created in a short space of time, or how many distinguishable novel features a design has, there are, however, different ways of assessing creativity which are more qualitative.

The art world provides an alternative perspective on the nature of creative output. In fact, the qualities which lead individuals with autism to perform poorly on psychological measures of creativity are highly valued by the art community. Key features of performance by individuals with autism on divergent thinking tasks are repetition of images with minimal discernable differences, the slow and highly detailed elaboration of one image rather than the rapid creation of many and 
the obsessive expression of images associated with a restricted area of interest. All of these qualities are widely demonstrated in the work of artists who are qualitatively judged by the art community to be exceptional in the creative production of imaginative work.

A recurring theme among great artists is the obsessive and consuming interest with a particular subject. For example, Paul Cézanne, the 'father of modern art' obsessively pursued an interest in representation of nature. Cézanne's work is characterised by studies around specific subject matter over a period of time, For example, over a hundred representations of 'The Bathers' were presented at the Basel Museum of Fine arts exhibition Paul Cézanne: The Bathers in 1989. Cézanne was similarly obsessed with the representation of the Saint-Victoire mountain. He writes to Emile Bernard:

...the monotony caused by the incessant pursuit of the sole and unique aim, which leads in moments of physical fatigue to a kind of intellectual exhaustion...the obstinacy with which I pursue the realization of that part of nature. $^{22}$

Not only does Cézanne demonstrate a highly restricted area of interest, his work also reflects the repeated investigation of a subject matter expressed through a series of images which at least to the untrained eye appear highly similar (see Image 5).
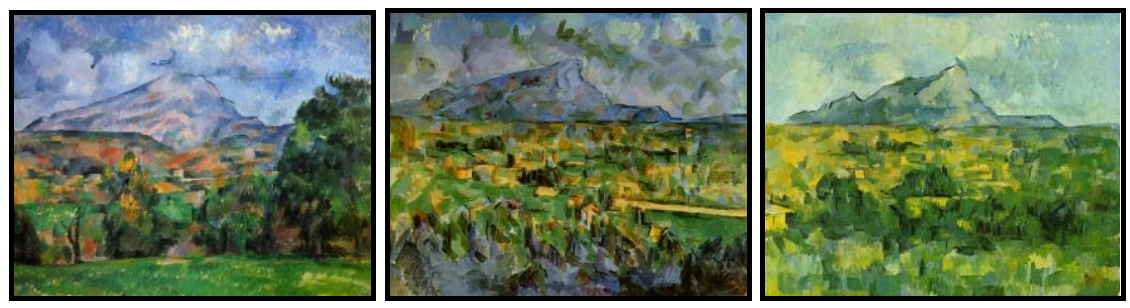

Image 5- 'Mount St. Victoire' Cézanne (1902-1906). Courtesy of www.awesomwart.biz. Licensed under Creative Commons Attribution 3 License: http://creativecommons.org/licenses/by-nd/3.0/

Cézanne is certainly far from unique in exploring a particular subject extensively with subtle changes of emphasis in the resulting works of art. Eminent examples include Monet's lilies, Degas' ballet dancers, Rothko's studies of colour fields and Picasso's guitars. In fact such an in depth research-based approach falls within the traditional art practice of forming a series or body of work around a particular stimulus. 
Recent interest in rehearsal and repetition in art across history including postmodernist practice is reflected in a growing literature and dedicated exhibitions exploring the topic. ${ }^{23}$ Recent interest extends to the use of repetition within works of art where the work itself is either a representation of an existing image or a composite of repeated images or objects with subtle differences between submotifs. Such work is common, but not exclusive to postmodern art, where repetition and reinvention act as a critique of the concept of originality on the one hand, but also as a response to high art's notions of authenticity. Sherrie Levine's work serves as a useful example. Levine's series 'After Cézanne' created in 2007 takes features of Cézanne's work and translates them into eighteen similar pixelated abstract images. Levine's Makonde Body Masks of the same year also uses repetition. Here identical bronze casts based on Tanzanian ritual objects hang in a line. Earlier eminent examples of the use of repetition include Warhol's silk screen images. Warhol uses repetition in a number of ways, including the creation of identical replicas, magnification and subtle changes ${ }^{24}$ exemplified in works such as his Marilyn prints (see Image 6).

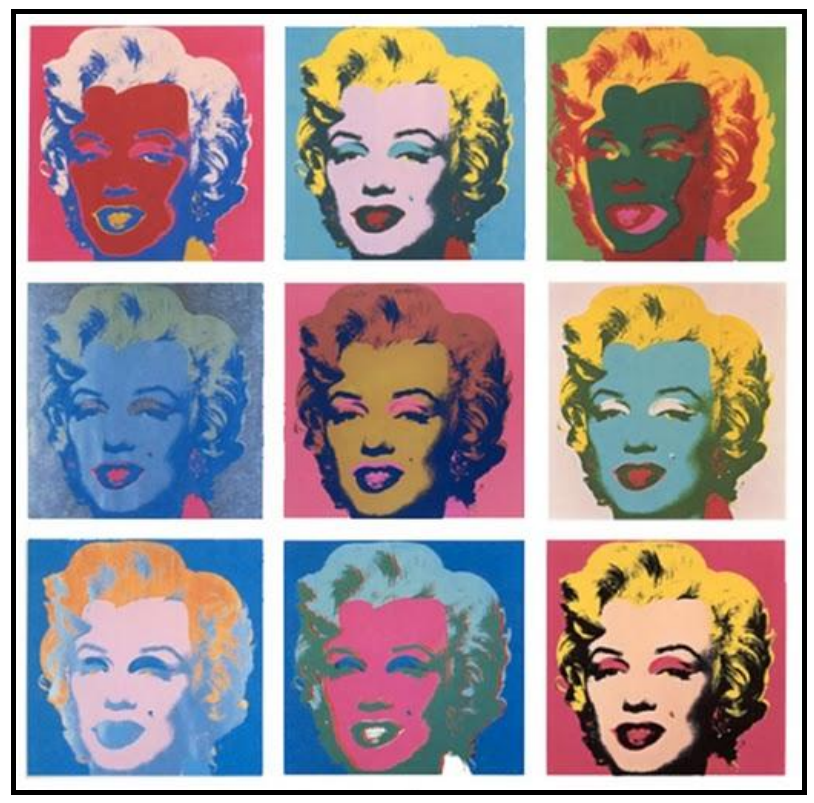

Image 6- 'Marilyn' Andy Warhol (1967). Courtesy of www.awesomw-art.biz. Licensed under Creative Commons Attribution 3 License: http://creativecommons.org/licenses/by-nd/3.0/ 
It seems that in the world of art at least, creativity is far from incompatible with the repetition of highly similar or associated images around a particular subject matter. Such subject matter may be pursued to obsessive proportions and reflect a highly restricted area of interest. The use of repetitive similar motifs is characteristic of some artists with autism, perhaps most notably, the acclaimed artist Gregory Blackstock. Blackstock typically sets out similar images in ordered rows or columns, ${ }^{25}$ each one drawn with extreme attention to detail (see Image 7).

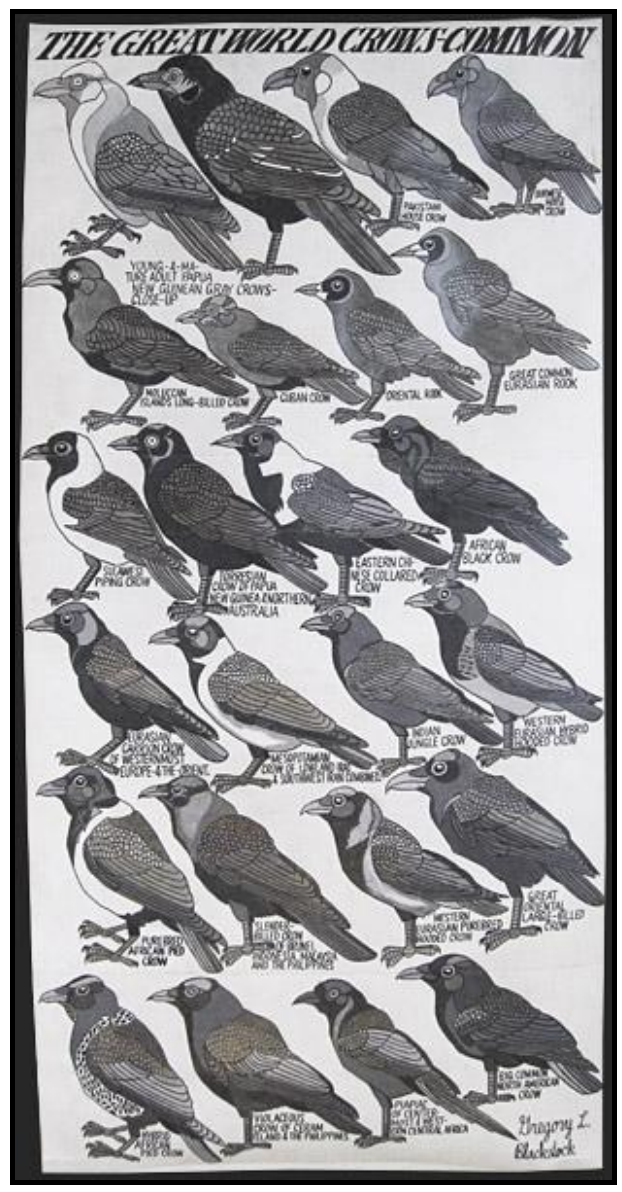

Image 7- 'The Great World Crows-Common' Gregory Blackstock (2009) Courtesy of Garde Rail Gallery 
Returning to our exploration of the creative output of individuals with autism, existing studies also emphasise the attention to detail and elaborative nature of responses to measures of creativity. Such an approach is necessarily in opposition to the rapid and multiple responses required by Torrance-like tests. Here once again, the world of art has a very different take. Artists who obsessively pursue a line of interest may spend years creating one highly detailed work rather than a plethora of solutions to the problem at hand. Masterpieces of this nature are abundant including Michelangelo's David and De Vinci's Mona Lisa. One particularly salient work is the internationally renowned masterpiece 'Girl with a Pearl Earring” by Vermeer (see Image 8). Vermeer's work is characterised by extreme care over long periods of time. Although little is known about the artist it is speculated that even at his most prolific he produced only three paintings during a year and a total of less than 40 pieces as his life time work.

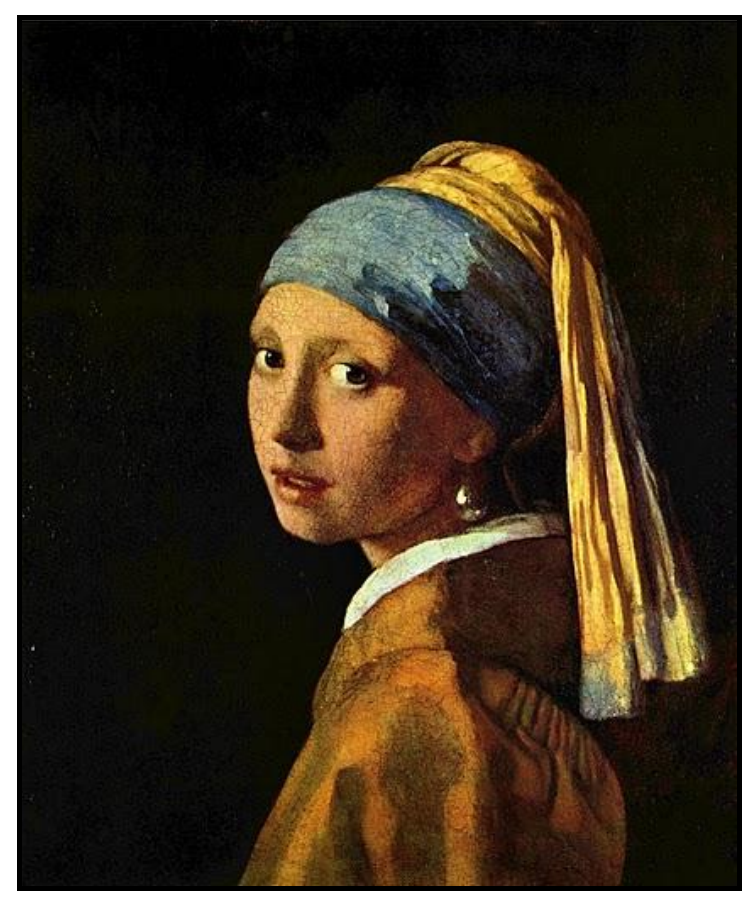

Image 8- 'Girl with a Pearl Earring'. Vermeer (circa 1665). Courtesy of www.awesomw-art.biz. Licensed under Creative Commons Attribution 3 License: http://creativecommons.org/licenses/by-nd/3.0/ 
The art community, the inspiring work of individuals with ASC and the reports of practitioners and parents of children with the condition, strongly suggest that there is huge creative potential within this special population. The current diagnostic criteria for autism and related conditions are unrepresentative of these various voices and deserve critical review. Similarly, commonly used psychological measures of creativity fail to reflect qualitative assessments, based upon evidence from art critics, experts, peers and historical bodies of work.

\section{Notes}

${ }^{1}$ Roger Cardinal, 'Outsider Art and the autistic creator', Phil.Trans. R. Soc. B 364, (2009): 1459-1466.

${ }^{2}$ Michel Thévoz, 'An Anti-Museum: The Collection de l'Art Brut in Lausanne', trans. Roger Cardinal, in The Artist Outsider: Creativity and the Boundaries of Culture, eds Michael D. Hall and Eugene W. Metcalf, Jr. (Washington D.C.: Smithsonian Institution Press, 1994), 63.

${ }^{3}$ Derren Jackson, 'Time to challenge the Rain Man stereotypes - the autistic mind can be spectacularly creative', TES, 27 May 2011, 25.

${ }^{4}$ Alexander DeLisle, 'Contextual collaboration in practice' (Undergraduate project, University of Plymouth, 2007)

${ }^{5}$ Debra Hosseini, Artism: the Art of Autism (Alberta: Sicoli Group Inc, 2011)

${ }^{6}$ World Health Organization. International classification of diseases (10th ed.), (Geneva, Switzerland, 1992) 199.

7 Jason Low, Elizabeth Goddard and Joseph Melser, 'Generativity and imagination in autism spectrum disorder: Evidence from individual differences in children's impossible entity drawings', British Journal of Developmental Psychology 27 (2009): 425-444.

${ }^{8}$ Dorothy V. M. Bishop and Courtney Frazier Norbury, 'Executive functions in children with communication impairments, in relation to autistic symptomatology I: Generativity', Autism 9 (1) (2005) 1362-3613.

${ }^{9}$ Michelle Turner, 'Generating novel ideas: fluency performance in highfunctioning and learning disabled individuals with autism', The Journal of Child Psychology and Psychiatry 40 (2) (1999): 189-201.

10 Jaime Craig and Simon Baron-Cohen, 'Creativity and Imagination in Autism and Asperger Syndrome', Journal of Autism and Developmental Disorders 29 (4) (1999) 319-326.

${ }^{11}$ Arlene Rosenthal, Stephen T. Demers, William Stilwell, Sheila Graybeal and Joseph Zins, 'Comparison of interrater reliability on the torrance tests of creative thinking for gifted and nongifted students', Psychology in the Schools 20 (1) (1983) 25-30. 
${ }^{12}$ Marilyn Jones-Gotman and Brenda Milner, 'Design fluency: The invention of nonsense drawings after focal cortical lesions', Neuropsychologia 15 (1977) 653674

${ }^{13}$ Frank E. Williams, 'The cognitive-affective interaction model for enriching gifted programs', In Systems and models for developing programs for the gifted and talented, ed. J.S. Renzulli. (Highett, Vic.: Hawker Brownlow, 1993), 461-484. ${ }^{14}$ Low et al., 'Generativity and Imagination', 431.

${ }^{15}$ Fiona Scott and Simon Baron-Cohen, 'Imagining real and unreal things:

Evidence of a dissociation in autism', Journal of Cognitive Neuroscience 8 (1996) 371-382.

${ }^{16}$ Jaime Craig, Simon Baron-Cohen and Fiona Scott, 'Drawing ability in autism: A window into the imagination', Israel Journal of Psychiatry 3 (2001) 242-253.

${ }^{17}$ Craig et al., 'Drawing ability in autism', 242-253.

${ }^{18}$ Craig and Baron-Cohen, 'Creativity and Imagination', 319-326.

${ }^{19}$ Meng-jung Lui, Wei-Lin Shih and Le-Yin Ma, 'Are children with Asperger syndrome creative in divergent thinking and feeling? A brief report', Research in Autism Spectrum Disorders 5 (2011) 294-298.

${ }^{20}$ Uta Frith, Autism: explaining the Enigma (Oxford, UK: Blackwell Publishing, 1989)

${ }^{21}$ Jane Duckett (1976) 'Idiot Savants: Super Specialization in Mentally Retarded Persons' (PhD diss., University of Texas at Austin, 1976)

${ }^{22}$ Paul Cézanne, Cézanne's letters, ed. J. Rewald, 1941 (Oxford, IA6, 1976)

${ }^{23}$ Patricia Mainardi, Viewed 22 June 2011, <http://www.19thc-

artworldwide.org/index.php/spring08/102-deja-vu-revealing-repetition-in-frenchmasterpieces>

${ }^{24}$ William S. Wilson, Revised preface to Prince of Boredom: The repetitions and Passivities of Andy Warhol, by W.S. Wilson, Viewed 22 June 2011, <http://www.warholstars.org/andywarhol/articles/william/wilson.html>

${ }^{25}$ Gregory L. Blackstock, Blackstock's Collections: The Drawings of an Artistic Savant (New York: Princeton Architectural Press, 2006)

\section{Bibliography}

Bishop, Dorothy V. M., and Norbury, Courtney Frazier.'Executive functions in children with communication impairments, in relation to autistic symptomatology I: Generativity'. Autism 9 (1) (2005) 1362-3613.

Blackstock, Gregory L. Blackstock's Collections: The Drawings of an Artistic Savant. New York: Princeton Architectural Press, 2006. 
Cardinal, Roger. 'Outsider Art and the autistic creator'. Phil. Trans. R. Soc. B 364 (2009): 1459-1466.

Cézanne, Paul. Cézanne’s letters, edited by J. Rewald, 1941. Oxford, IA6, 1976.

Craig, Jaime., and Baron-Cohen, Simon. 'Creativity and Imagination in Autism and Asperger Syndrome'. Journal of Autism and Developmental Disorders 29 (4) (1999) 319-326.

Craig, Jaime., Baron-Cohen, Simon., and Scott, Fiona. 'Drawing ability in autism: A window into the imagination'. Israel Journal of Psychiatry 3 (2001) 242-253.

DeLisle, Alexander. 'Contextual collaboration in practice'. Undergraduate project, University of Plymouth, 2007.

Duckett, Jane. (1976) 'Idiot Savants: Super Specialization in Mentally Retarded Persons'. PhD diss., University of Texas at Austin, 1976.

Frith,Uta. Autism: explaining the Enigma. Oxford, UK: Blackwell Publishing, 1989.

Hermelin, Beate. Bright Splinters of the Mind: A Personal Story of Research with Autistic Savants. London: Jessica Kingsley, 2002.

Hosseini, Debra. Artism: the Art of Autism. Alberta: Sicoli Group Inc, 2011.

Jackson, Derren .'Time to challenge the Rain Man stereotypes - the autistic mind can be spectacularly creative', TES, 27 May 2011, 25.

Jones-Gotman, Marilyn., and Milner, Brenda. 'Design fluency: The invention of nonsense drawings after focal cortical lesions'. Neuropsychologia 15 (1977) 653674

Leevers, Hilary J., and Harris, Paul L. (1998) 'Drawing Impossible Entities: A Measure of the Imagination in Children with Autism, Children with Learning Disabilities, and Normal Four-year-olds'. Journal of Child Psychology and Psychiatry 39 (1998) 399-410.

Lui, Meng-jung., Shih, Wei-Lin., and Ma, Le-Yin. 'Are children with Asperger syndrome creative in divergent thinking and feeling? A brief report'. Research in Autism Spectrum Disorders 5 (2011) 294-298. 
Low, Jason., Goddard, Elizabeth., and Melser, Joseph. 'Generativity and imagination in autism spectrum disorder: Evidence from individual differences in children's impossible entity drawings'. British Journal of Developmental Psychology 27 (2009): 425-444.

Mainardi, Patricia. Accessed 22 June 2011, <http://www.19thcartworldwide.org/index.php/spring08/102-deja-vu-revealing-repetition-in-frenchmasterpieces>

O'Connor, Neil., and Hermelin, Beate. 'Visual and Graphic Abilities of the Idiot Savant Artist', Psychological Medicine 17 (1987) 79-90.

Rosenthal, Arlene., Demers, Stephen T., Stilwell, William., Graybeal, Sheila., and Zins, Joseph. 'Comparison of interrater reliability on the torrance tests of creative thinking for gifted and nongifted students'. Psychology in the Schools 20 (1) (1983) 25-30.

Sacks, Oliver. Stephen Wiltshire, 'Prodigies'. In An anthropologist on Mars. Seven paradoxical tales. 179-232. London, UK: Picador, 1995.

Selfe, Lorna. (1977) Nadia: A Case of Extraordinary Drawing Ability in an Autistic Child. London: Academic Press, 1977.

Scott, Fiona., and Baron-Cohen, Simon. 'Imagining real and unreal things: Evidence of a dissociation in autism'. Journal of Cognitive Neuroscience 8 (1996) 371-382.

Thévoz, Michel. 'An Anti-Museum: The Collection de l'Art Brut in Lausanne'. trans. Roger Cardinal, in The Artist Outsider: Creativity and the Boundaries of Culture, edited by Michael D. Hall and Eugene W. Metcalf, Jr., 63. Washington D.C.: Smithsonian Institution Press, 1994.

Treffert, Darrold. 'The Savant Syndrome: An Extraordinary Condition. A Synopsis: Past, Present, Future'. Philosophical Transactions of the Royal Society B: Biological Sciences 364 (2009) 1351-8.

Turner, Michelle. 'Generating novel ideas: fluency performance in highfunctioning and learning disabled individuals with autism'. The Journal of Child Psychology and Psychiatry 40 (2) (1999): 189-201. 
Williams, Frank E. 'The cognitive-affective interaction model for enriching gifted programs'. In Systems and models for developing programs for the gifted and talented, edited by J.S. Renzulli, 461-484. Highett, Vic.: Hawker Brownlow, 1993.

Wilson, William S. Revised preface to Prince of Boredom: The repetitions and Passivities of Andy Warhol, by W.S. Wilson, Accessed 22 June 2011, <http://www.warholstars.org/andywarhol/articles/william/wilson.html>

World Health Organization. International classification of diseases (10th ed.). Geneva, Switzerland, (1992) 199.

Rebecca McKenzie is a developmental psychologist and lecturer in education at the University of Plymouth UK. Her main research interest is thinking and reasoning among adults and children with autism spectrum conditions. 